Proof of concept review

\title{
Roflumilast: the evidence for its \\ clinical potential in the treatment of \\ chronic obstructive pulmonary disease
}

\author{
Linda Timm Wagner, Charlotte A. Kenreigh \\ MLC Solutions Ltd, Galena, Ohio, USA
}

\begin{abstract}
Introduction: Chronic obstructive pulmonary disease (COPD), characterized by a progressive deterioration of lung function caused primarily by the inhalation of toxic substances, is a leading cause of morbidity and mortality worldwide. Current treatment options for the management of its symptoms include the use of bronchodilators and glucocorticoid agents that are not universally beneficial and which are associated with limitations. Phosphodiesterase-4 (PDE4) inhibitors are a novel class of antiinflammatory agents being developed for COPD treatment.
\end{abstract}

Aims: The purpose of this article is to review the clinical potential of roflumilast, a PDE4 inhibitor currently in phase III clinical trials, in the management of patients with COPD.

Evidence review: Phase II studies indicate that roflumilast can be given orally once daily. Preliminary evidence from two phase III, randomized, double-blind, placebo-controlled studies suggest that roflumilast improves or stabilizes lung function, as measured by forced expiratory volume in $1 \mathrm{~s}$ and $6 \mathrm{~s}$ (FEV 1 and $\mathrm{FEV}_{6}$ ), forced vital capacity (FVC), and peak expiratory flow (PEF) in patients with COPD. Improvements in COPD exacerbation rate were also reported in these trials. Quality of life, as measured by the St George's Respiratory Questionnaire, also improved with roflumilast treatment. Clinical studies to date suggest that roflumilast is well tolerated.

Clinical potential: Current evidence supports the use of roflumilast in the management of COPD as shown by improvements in patients' symptoms and quality of life, and good tolerability profile. Its once-daily oral dosing regimen is unique among current therapies for COPD. This potential and the place of roflumilast in the stepwise management of the disease need to be confirmed as further evidence is published. Additional evidence will also be welcome to determine if its mechanism of action moderates the progression of lung function deterioration.

Key words: roflumilast, COPD, evidence, outcomes, treatment

\section{Core evidence proof of concept summary for roflumilast in chronic obstructive pulmonary disease}

\begin{tabular}{|l|l|}
\hline Outcome measure & Emerging evidence \\
\hline Patient-oriented evidence & Dose-dependent decrease in exacerbation rate \\
Number of acute exacerbations of COPD & Statistically significant improvements in SGRQ scores \\
Disease-oriented evidence & Roflumilast improves or stabilizes lung function \\
\hline Lung function as measured by $\mathrm{FEV}_{1}, \mathrm{FEV}_{6}, \mathrm{FVC}, \mathrm{PEF}$ & \\
\hline FEV , forced expiratory volume in $1 \mathrm{~s} ; \mathrm{FEV}_{6}$, forced expiratory volume in $6 \mathrm{~s} ; \mathrm{FVC}$, forced vital capacity; PEF, peak expiratory flow; QOL, quality of life; SGRQ, St George's Respiratory Questionnaire. \\
\hline
\end{tabular}




\section{Scope, aims, and objectives}

Roflumilast (ALTANA Pharma AG), a phosphodiesterase-4 (PDE4) inhibitor, is being developed for the management of chronic obstructive pulmonary disease (COPD) and asthma. Its once-daily oral administration may be advantageous in the treatment of these respiratory diseases. Pharmacologically, the PDE4 inhibitors represent a new class of antiinflammatory agents. Preliminary data from phase III clinical trials evaluating roflumilast in the management of patients with COPD are available. Another PDE4 inhibitor, cilomilast (GlaxoSmithKline), has also been evaluated for patients with COPD.

The purpose of this article is to review unmet needs in the management of patients with COPD, and the clinical potential of roflumilast based on the available evidence.

\section{Methods}

The English language medical literature was reviewed for appropriate articles relating to roflumilast for the treatment of COPD. The search terms were "roflumilast," "APTA 2217," "B9302107," "BY 217," "Daxas," and "BYK 20869," and the following databases were searched during January and February, 2005:

- PubMed, www.ncbi.nlm.nih.gov/entrez

- EMBASE, www.datastarweb.com

- Database of Abstracts of Reviews of Effectiveness (DARE), NHS Economic Evaluations Database (NHSEED), Health Technology Assessment (HTA), www.york.ac.uk/inst/crd/darehp.htm

- NHS HTA, www.ncchta.org

- National Guidelines Clearinghouse, www.guideline.gov

- National Institute for Health and Clinical Excellence (NICE), www.nice.org.uk

- Cochrane Database of Systematic Reviews, www.cochrane.org

- Clinical Evidence, www.clinicalevidence.com

Table 1 | Evidence base included in the review

\begin{tabular}{|lcc|} 
& \multicolumn{2}{c|}{ Number of records } \\
\cline { 2 - 3 } Category & Full papers & Abstracts \\
\hline $\begin{array}{l}\text { Initial search } \\
\quad \text { records excluded }\end{array}$ & 19 & 62 \\
$\quad$ records included & 17 & 31 \\
Additional studies identified & 2 & $31^{\text {a }}$ \\
Level 1 clinical evidence & 0 & N/A \\
Level 2 clinical evidence & 2 & 0 \\
Level $\geq 3$ clinical evidence & 0 & $31^{\text {b }}$ \\
trials other than RCT & & 0 \\
$\quad$ case reports & 0 & 0 \\
Economic evidence & 0 & 0 \\
\hline aStudy results presented at two meetings were reviewed together. \\
bStudy design and quality cannot be assessed from abstract. \\
N/A, not available; RCT, randomized controlled trial. & 0 & \\
\hline
\end{tabular}

No date limitations were placed on the search and only studies in patients with COPD were included. Abstracts from the American Thoracic Society (ATS) and the European Respiratory Society (ERS) meetings from 2001 to 2004 were also reviewed using the same search terms to identify any studies that have not yet been published in full. Thirty-one abstracts with results from randomized controlled trials were identified.

The levels of evidence identified from the literature searches are summarized in Table 1 (see Editorial Information on inside back cover).

\section{Disease overview}

COPD, a progressive respiratory disease characterized by gradual loss of lung function and airflow obstruction that is not fully reversible, is a leading cause of morbidity and mortality worldwide. In developed countries, it has been estimated that COPD occurs in $4-10 \%$ of the population (Halbert et al. 2003; Pauwels \& Rabe 2004). However, since COPD definitions differ among clinicians and diagnosis does not generally occur early in the disease course, these figures are probably an underestimation of its true incidence. Currently, COPD is the fourth leading cause of death in the USA (NHLBI 2005), while the World Health Organization (WHO) ranks it as the fifth most common cause of death worldwide (WHO 2005). It is estimated that COPD will be the third leading cause of death globally by the year 2020 (Murray \& Lopez 1997; NHLBI 2005).

Unlike other chronic conditions such as heart disease and cancer, mortality of COPD continues to increase (GOLD/WHO/NHLBI 2004). This is influenced by both the lack of early recognition of the disease and poor prevention strategies. Although symptoms may be absent in early COPD, as it progresses, chronic inflammation produces reduced airflow and hyperinflation that can lead to dyspnea, chronic cough, sputum production, and wheezing. The impact on the ability to perform activities of daily living can be significant in those who experience dyspnea.

The chronic lung inflammation that is responsible for COPD is primarily caused by inhalation of toxic substances, with cigarette smoking being the most important risk factor. In general, the disease is diagnosed in patients over 40 years of age. However, in the USA, COPD is often diagnosed in 30-40 year olds. This earlier age of diagnosis is most likely the result of an earlier exposure to inhaled toxins because smoking occurs at an earlier age in the US population (Briggs 2004).

Although the costs associated with COPD differ among reporting countries (Halbert et al. 2003), they are all significant. The total estimated costs in 2002 in the USA were \$US32.1 billion, with \$US18 billion in direct costs (NHLBI 2005). In the UK, the total annual cost of COPD has been estimated to be £982 million (NICE 2004). Estimated costs associated with sickness benefit and working days lost are over $£ 1.5$ billion per year in the UK (1996 estimation) (GOLD/WHO/NHLBI 2004).

The Confronting COPD International Survey attempted to quantify the burden of disease and morbidity in patients with COPD (Rennard et al. 2002). Almost 13\% of participants reported at least one hospitalization in the previous year, and nearly $14 \%$ reported requiring emergency care. Again, it is expected that these estimates of the true burden of COPD are low. 


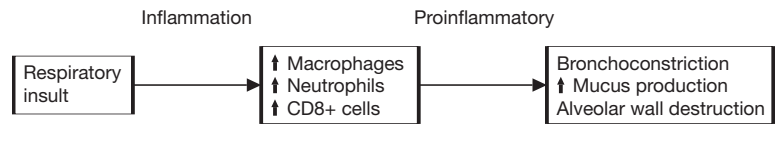

cytokines

Fig. 1 | Inflammatory process in chronic obstructive pulmonary disease

COPD is described as a process of chronic inflammation that results in narrowing of the bronchi. The inflammatory process initiates other changes that affect pulmonary function, including mucous gland hypertrophy, goblet cell hyperplasia, peribronchiolar fibrosis, and thickening of the pulmonary vasculature (NICE 2004). The inflammatory changes of COPD differ from that of asthma. In asthma the inflammatory process is primarily a CD4+ T-cell-driven eosinophilia, whereas in COPD, the inflammatory process includes an increase in the numbers and/or activity of CD8+ $\mathrm{T}$ cells, macrophages, and neutrophils (Fig. 1) (Sturton \& Fitzgerald 2002). Therapies that interrupt or prevent the inflammation are ideal candidates for modifying these inflammatory diseases.

Nonselective PDE inhibitors, such as theophylline, increase cyclic adenosine monophosphate (cAMP) producing bronchial smooth muscle relaxation and suppression of the inflammatory response. Most recent research has found that theophylline does not exert PDE inhibition to a pharmacodynamically or clinically meaningful extent (only 5-10\% PDE inhibition at therapeutic serum levels); adenosine-A2 antagonism and histone deacetylase stimulation appear to be the more dominant modes of action (Soto \& Hanania 2005). Additionally, the widespread use of theophylline in the management of COPD is limited by its narrow therapeutic index and potential for drug-drug interactions. Further research into PDE inhibition has led to the identification of at least 11 PDE enzymes (Lipworth 2005). Current research is focused on targeting these specific isoenzymes.

PDE4 is found in inflammatory and immune cells and is the primary enzyme responsible for the regulation of metabolism and inactivation of CAMP in these cells as well as in airway smooth muscles. Inhibition of PDE4 has been associated with relaxation of airway smooth muscle, suppression of the activation of inflammatory cells, and modulation of pulmonary nerves (Fig. 2) (Sturton \& Fitzgerald 2002; Spina 2003; Lipworth 2005). In bronchial biopsies, PDE4 inhibition has been linked to a decrease in the

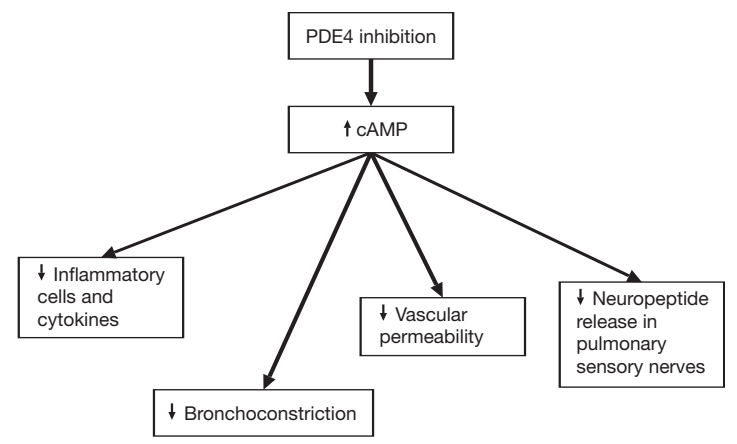

Fig. 2 | Effects of phosphodiesterase-4 inhibition number of CD8+ lymphocytes, macrophages, and neutrophils (Gamble et al. 2003). Both in vitro and in vivo data indicate PDE4 inhibition produces antiinflammatory activity in cells (e.g. neutrophils) linked to COPD airway inflammation (Soto \& Hanania 2005). PDE4 inhibitors therefore offer a novel antiinflammatory mechanism of action that differs from steroidal antiinflammatory medications.

\section{Current therapy options}

Guidelines for the management of COPD have been published by several different organizations. The WHO and the National Heart Lung and Blood Institute have joined together to form the Global Initiative for Chronic Obstructive Lung Disease (GOLD) and published initial guidelines in 2001 with annual review and updates (GOLD/WHO/NHLBI 2004). The ATS and the ERS have also published a position paper on COPD (ATS/ERS 2005). In addition, the National Institute for Health and Clinical Excellence (NICE) in England and Wales recently released guidelines for the management of patients with COPD (NICE 2004). All of these guidelines review prevalence, diagnosis, and management, and, although each differs in the specific classification of patients with COPD, they all recommend managing stable COPD with a stepped-care approach.

Currently there is no cure for COPD and no pharmacologic intervention is able to alter the rate of lung function decline. Treatment goals include smoking cessation, reducing the risk of further disease progression, management of symptoms, improving physiologic function, and limiting disease complications (GOLD/WHO/NHLBI 2004; ATS/ERS 2005)

\section{Smoking cessation}

The only COPD intervention that has demonstrated a reduction in the decline in lung function is smoking cessation (Sutherland \& Cherniak 2004), which can alter the course of airflow limitation or diminish its progression (GOLD/WHO/NHLBI 2004). However, because smoking is often a very difficult habit to break, it is recommended that patients receive both counseling and pharmacologic intervention to support them during the withdrawal process. All the guidelines recommend smoking cessation as one of the single most important interventions in COPD (GOLD/WHO/NHLBI 2004; NICE 2004; ATS/ERS 2005). Avoidance of other known respiratory irritants, such as occupational fumes and dusts, and biomass fuels, is also recommended. Although smoking cessation is an important goal, interventions are not effective for all individuals with COPD, thus other therapies must be used to manage the symptoms of the disease, reduce the frequency and severity of exacerbations, and improve exercise tolerance.

\section{Symptom management}

Shortness of breath is the symptom that is most often treated, since it is most closely related to quality of life and health status (GOLD/WHO/NHLBI 2004; NICE 2004; ATS/ERS 2005). Treatment of complications, such as exacerbations and hypoxemia, include providing oxygen and managing exacerbations with antibiotics, glucocorticoids, and bronchodilators. Treatment options for COPD include bronchodilators and antiinflammatory agents, the former are central to the symptomatic management of patients with COPD 
Table 2 | Pharmacologic agents used in the management of chronic obstructive pulmonary disease (COPD) (GOLD/WHO/NHLBI 2004; NICE 2004)

\begin{tabular}{|lll} 
Drug class & $\begin{array}{l}\text { Route of } \\
\text { administration }\end{array}$ & Potential adverse effects Advantages
\end{tabular}

\section{Beta $_{2}$ agonists}

Short-acting

Fenoterola $^{a}$

Albuterol (salbutamol)

Terbutaline

Long-acting

Formoterol

Salmeterol
Inhaled ${ }^{b}$

Tachycardia, hypokalemia, skeletal muscle tremor, prolongation of $\mathrm{QT}_{\mathrm{c}}$ interval, headache, hyperglycemia

Dry mouth,

blurred vision

Short-acting

Ipratropium

Inhaled

Long-acting

Tiotropium

Combination short-acting beta $_{2}$ agonist/anticholinergic

Fenoterol/ipratropium $^{\mathrm{a}}$

Salmeterol/ipratropium

Inhaled

Same as individual components

\section{Methylxanthines}

Aminophylline

Oral

Theophylline$$
\text { Ora }
$$

Tachycardia, nausea, vomiting, tachyarrhythmia, seizures, headaches, CNS stimulation, hypokalemia, hyperglycemia

\section{Glucocorticoids (inhaled)}

Beclomethasone Inhaled Cough, dysphonia, oral

Budesonide thrush

Fluticasone

Triamcinolone

\section{Combination long-acting beta ${ }_{2}$ agonist/glucocorticoid}

Formoterol/budesonide ${ }^{a}$ Inhaled

Salmeterol/fluticasone

Same as individual

components

Glucocorticoids (systemic)

Prednisone Oral

Methylprednisolone
Steroid myopathy, adrenal suppression, osteoporosis
Central to the management of COPD

Short-acting agents can be used on an "as needed" basis; rapid onset of action

Reduce breathlessness, improve dyspnea, fatigue and $\mathrm{FEV}_{1}$

Regular use of long-acting agents more effective and convenient that short-acting agents

Long-acting agents reduce night awakenings

Regular use of long-acting agent improves health status

Regular use of long-acting agent improves health status Improves exercise tolerance, dyspnea, and fatigue

Increases $\mathrm{FEV}_{1}$ and FVC, improves wheezing and dyspnea

Greater and more sustained improvement in $\mathrm{FEV}_{1}$ than with single agents

Improve exercise tolerance, $\mathrm{FEV}_{1}$, FVC, health status, lung volume, and dyspnea

Regular use reduces frequency of exacerbations and improves health status

Combination therapy more effective than individual agents
Long-acting agents more costly

Patient must be able to use inhaler device effectively

Patient must be able to use inhaler device effectively

Patient must be able to use inhaler device effectively

Narrow therapeutic index Potential for significant adverse effects and drug interactions

Does not modify long-term decline in $\mathrm{FEV}_{1}$

Minimal effect on airway responsiveness

Patient must be able to use inhaler device effectively

Patient must be able to use inhaler device effectively

No evidence of long-term benefit

Systemic adverse effects associated with long-term oral use 
Table 3 | Pharmacologic management of chronic obstructive pulmonary disease (COPD) (adapted from GOLD/WHO/NHLBI 2004)

\begin{tabular}{|c|c|c|}
\hline Stage of COPD & Characteristics & Management strategy \\
\hline \multirow[t]{3}{*}{ At risk } & Chronic symptoms (cough, sputum production) & Avoidance of risk factors \\
\hline & Exposure to risk & Influenza vaccination \\
\hline & Normal spirometry & \\
\hline \multirow[t]{3}{*}{ Mild } & $\mathrm{FEV}_{1} / \mathrm{FVC}<70 \%$ & Avoidance of risk factors \\
\hline & $\mathrm{FEV}_{1} \geq 80 \%$ predicted & Influenza vaccination \\
\hline & With or without symptoms & Short-acting bronchodilator as needed \\
\hline \multirow[t]{4}{*}{ Moderate } & $\mathrm{FEV}_{1} / \mathrm{FVC}<70 \%$ & Avoidance of risk factors \\
\hline & $50 \% \leq \mathrm{FEV}_{1}<80 \%$ predicted & Influenza vaccination \\
\hline & With or without symptoms & Short-acting bronchodilator as needed \\
\hline & & Regular treatment with one or more long-acting bronchodilators \\
\hline \multirow[t]{5}{*}{ Severe } & $\mathrm{FEV}_{1} / \mathrm{FVC}<70 \%$ & Avoidance of risk factors \\
\hline & $30 \% \leq \mathrm{FEV}_{1}<50 \%$ predicted & Influenza vaccination \\
\hline & With or without symptoms & Short-acting bronchodilator as needed \\
\hline & & Regular treatment with one or more long-acting bronchodilators \\
\hline & & Addition of inhaled corticosteroids if repeat exacerbations \\
\hline \multirow[t]{6}{*}{ Very severe } & $\mathrm{FEV}_{1} / \mathrm{FVC}<70 \%$ & Avoidance of risk factors \\
\hline & $\mathrm{FEV}_{1}<30 \%$ or $\mathrm{FEV}_{1}<50 \%$ predicted with & Influenza vaccination \\
\hline & & Short-acting bronchodilator as needed \\
\hline & & Regular treatment with one or more long-acting bronchodilators \\
\hline & & Addition of inhaled corticosteroids if repeat exacerbations \\
\hline & & Long-term oxygen for respiratory failure \\
\hline \multirow[t]{2}{*}{ Exacerbations } & & $\begin{array}{l}\text { Inhaled bronchodilators, theophylline, and systemic (preferably oral) glucocorticoids } \\
\text { are effective treatments for exacerbations of COPD }\end{array}$ \\
\hline & & Airway infection may be treated with antibiotics \\
\hline
\end{tabular}

(Table 2). At present (due to availability), the inhaled route of drug administration is preferred for the management of COPD. This route allows the direct application of a medication to the desired site of action with a lower dose and a reduced risk of systemic adverse events.

The stepwise approach to the treatment of patients with COPD, as suggested by GOLD, is outlined in Table 3. Similar approaches are found in the guidelines issued by NICE (2004) and ATS/ERS (2005).

\section{Bronchodilators}

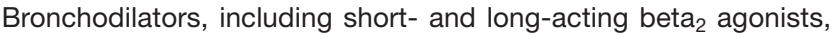
anticholinergic agents, and theophylline relax smooth muscles in the airway, improve lung emptying during tidal breathing, and increase forced expiratory volume in $1 \mathrm{~s}\left(\mathrm{FEV}_{1}\right)$. These agents have also been shown to improve exercise tolerance in patients with COPD. Although bronchodilators improve symptoms and healthrelated quality of life (HRQOL), their use has not demonstrated statistically significant improvements in exacerbation rates (GOLD/WHO/NHLBI 2004; NICE 2004; ATS/ERS 2005). Beta agonists and anticholinergic agents are preferred over the use of theophylline in the management of COPD. These agents also reduce static and dynamic hyperinflation; this pharmacodynamic property may explain the clinical benefits beyond changes in $\mathrm{FEV}_{1}$ (i.e. reduction in breathlessness) (NICE 2004).
Because short-acting bronchodilators have a rapid onset of activity, they can be used effectively as rescue medications. The long-acting bronchodilators should generally be reserved for maintenance therapy (GOLD/WHO/NHLBI 2004; NICE 2004; ATS/ERS 2005). As a rule, their slower onset of action (with the exception of formoterol) minimizes their usefulness in acute situations.

Theophylline and its derivatives are not available in an inhaled formulation and must be taken orally for chronic use. However, high doses are often required, which can be associated with significant toxicities (see Table 2). Additional mechanisms of action have been attributed to theophylline, including antiinflammatory effects and activation of histone deacetylases (Barnes 2003). The clinical importance of these additional mechanisms has not been established (GOLD/WHO/NHLBI 2004; NICE 2004; ATS/ERS 2005).

The oral slow-release preparations of theophylline have been shown to have a positive effect on $\mathrm{FEV}_{1}$, lung volume, dyspnea, HRQOL, and exercise endurance (GOLD/WHO/NHLBI 2004). However, significant adverse events and clinically significant drug-drug and drug-disease interactions limit their usefulness in the clinical setting. Additionally, there are no published data to support any effect of theophylline on the exacerbation rate (GOLD/WHO/NHLBI 2004; NICE 2004; ATS/ERS 2005). 


\section{Glucocorticoids}

Glucocorticoids have activity at multiple points in the inflammatory cascade; however, their beneficial effects in patients with COPD are less impressive than in those with asthma. Glucocorticoids have minimal effects on neutrophils and macrophages, which are central to the inflammatory destruction associated with COPD (see Fig. 1) (Sturton \& Fitzgerald 2002). In patients with chronic COPD, inhaled glucocorticoids produce a small increase in postbronchodilator $\mathrm{FEV}_{1}$ and a small decrease in bronchial reactivity (GOLD/WHO/NHLBI 2004; NICE 2004; ATS/ERS 2005). In addition to their effect on $\mathrm{FEV}_{1}$, administration of inhaled corticosteroids has been associated with a positive impact on HRQOL and a decrease in exacerbation frequency, particularly in patients with more advanced disease (GOLD/WHO/NHLBI 2004; NICE 2004; ATS/ERS 2005). Although the impact on airway responsiveness is less than optimal, the decreases in exacerbations and improvements in health status make inhaled glucocorticoids an option for those patients with frequent exacerbations and those with more severe disease. It is important to note that controversy regarding the use of glucocorticoids exists and individual studies have reported differing responses to their use (Alsaeedi et al. 2002; Highland et al. 2003; Bonay et al. 2005).

Glucocorticoids are also available as oral agents. However, due to the preponderance of adverse effects associated with their longterm oral administration they are reserved for the management of acute exacerbations. Administration of corticosteroids via the inhaled route can also result in systemic absorption and associated adverse events; however, these are considerably less frequent than with oral administration.

\section{Combination products}

Combination therapy may be beneficial in patients with COPD. Although beta $_{2}$ agonists, anticholinergic agents, and theophylline are all bronchodilators, each class has a different mechanism of action. Therefore, combining medications from different pharmacologic classes may improve symptoms in patients with COPD and minimize the development of adverse events. Combinations of a beta ${ }_{2}$ agonist and an anticholinergic agent, a beta $_{2}$ agonist and theophylline, an anticholinergic agent and theophylline, and a long-acting beta ${ }_{2}$ agonist and an inhaled corticosteroid have shown effectiveness in clinical studies and may be beneficial in patients who require an increase in pharmacologic support (NICE 2004). Preparations of beta ${ }_{2}$ agonists in combination with either an anticholinergic agent or glucocorticoid are commercially available (see Table 2).

\section{Other therapies}

There are other, less frequently used, treatments that have not shown consistent evidence of benefit in patients with COPD. Mucolytics, alpha trypsin augmentation, leukotriene receptor antagonists, maintenance antibiotic administration, immunoregulators, respiratory stimulants, and vasodilators have either not shown consistent benefit or have an unattractive benefit to risk ratio in patients with COPD (GOLD/WHO/NHLBI 2004; NICE 2004; ATS/ERS 2005).

\section{Unmet needs}

As with most diseases, there are many opportunities for improvement in the management of patients with COPD. Despite the effectiveness of current pharmacologic therapies, the ideal agent has yet to be developed. Currently available treatments do not alter the progressive decline in lung function: rather they mitigate symptoms and/or reduce complications (GOLD/WHO/NHLBI 2004). Clearly, there is a need for treatments that can slow the progression of pulmonary disease, even if the process cannot be fully reversed. Although the role of inflammation in the pathogenesis of COPD has been identified, traditional inhaled and/or oral antiinflammatory agents have not demonstrated a significant impact on the progression of COPD (Sturton \& Fitzgerald 2002; Lipworth 2005). Oral administration of corticosteroids is associated with an unacceptable risk to benefit ratio in most patients, therefore only the inhaled route of administration is routinely used and, as stated above, these agents have minimal effect on $\mathrm{FEV}_{1}$ and their use is thus reserved for patients with more severe COPD. There remains a need for antiinflammatory/diseasemodifying therapy for the treatment of patients with COPD.

Beyond the absence of curative therapy, current treatment options have inherent limitations. Many of the orally available treatments are associated with significant adverse events. In most cases, the potential for adverse events outweighs the clinical benefit that could be derived from their long-term use as an oral agent. Thus, the successful use of oral therapies in the management of COPD has been met with limited success, and patients must use inhaled therapies as the foundation of their treatment. Although many patients can effectively use this type of formulation, others may have physical limitations (e.g. as a result of arthritis) that preclude their effective use. Additionally, the use of inhaled therapies can be a time-consuming process that requires diligent attention to administration technique to achieve optimal benefit. Inhaled pharmacotherapy requires patient counseling and education, not only at the initial visit, but also on an ongoing basis to determine whether the use of these treatments is optimal.

Adherence to therapy has been identified as another problem in patients with COPD. Because the goal of therapy is symptom relief, adherence to treatments for COPD would be expected to be high. However, adherence to bronchodilator therapy has been relatively poor; clinical studies evaluating patient adherence to therapy report an adherence rate between 40 and $70 \%$ (Make 2003). Factors associated with this poor adherence include administration technique-related errors and poorly perceived benefits of therapy.

Identification of an oral agent that produces beneficial effects (decreased disease progression and antiinflammatory effects) with a good tolerability profile would be a valuable addition to the available treatment options. The use of simplified regimens might also improve patient adherence to therapy and subsequently improve quality of life and decrease frequency of exacerbations.

\section{Outcomes achieved with roflumilast in clinical development}

Roflumilast is an orally active PDE4 inhibitor in phase III clinical development that shows promise in patients with COPD. Its 
mechanism of action may result in an improved risk to benefit profile for long-term use.

Since no treatment is currently available to alter the course of COPD, evaluations of interventions must focus on symptom improvement and functional status. Measurements of the effectiveness of a pharmacologic agent used in the management of stable COPD include changes in $\mathrm{FEV}_{1}$, exercise tolerance, improvements in quality of life and HRQOL, frequency of exacerbations, and dyspnea (Aaron et al. 2002; de Torres et al. 2002; Desikan et al. 2002; Domingo-Salvany et al. 2002; Fan et al. 2002; Jones 2002; Miravitlles et al. 2002; Wyrwich et al. 2003). The importance of the various outcomes differs depending on the judgment of the individual using or interpreting the data.

Despite being a disease-oriented outcome rather than a patientoriented outcome, improvement in $\mathrm{FEV}_{1}$ is often used as a standard measure of therapeutic effect because it is easy to measure. Consequently, it tends to be the measure that is used by clinicians to evaluate the effectiveness of treatments for COPD. Often FEV $\mathrm{Fis}_{1}$ used to indicate the presence or absence of dyspnea and to infer quality of life changes. However, studies have shown that patients may experience improvement in dyspnea without a corresponding change in $\mathrm{FEV}_{1}$ (GOLD/WHO/NHLBI 2004; NICE 2004; ATS/ERS 2005). For example, bronchodilators as a group produce relatively small changes in $\mathrm{FEV}_{1}$ yet they remain the cornerstone of COPD therapy because of their positive effects on other measures of symptom management, such as breathlessness and dyspnea. It is therefore important to recognize that other, more patient-centered, measures of treatment outcome should be used to better assess treatment effectiveness for an individual patient, in addition to $\mathrm{FEV}_{1}$.

Quality of life measures offer a patient perspective on treatment effects and disease symptoms. Improvement in symptoms, including exercise tolerance and dyspnea, can be linked to perceived improvements in quality of life and HRQOL. HRQOL measures include the ability to conduct activities of daily living; therefore, these tools are often excellent predictors of patient acceptance of a therapy. Many quality of life tools are available; the most commonly used instruments in COPD are summarized in Table 4. Unfortunately, the ideal assessment tool for measurement of COPD symptoms and quality of life has not yet been developed, and each tool has its strengths and weaknesses (de Torres et al. 2002; Desikan et al. 2002; Jones 2002; Wyrwich et al. 2003). Currently there is no consensus delineating the most appropriate HRQOL tool for use in patients with COPD.

Preliminary data from two phase III, randomized, parallel-group, double-blind, placebo-controlled clinical trials evaluating roflumilast in patients with COPD are available. The larger of the two, the RECORD study, included 1411 patients (FEV 1 of $30-80 \%$ of predicted with reversibility of $<12 \%$ ) (O'Donnell et al. 2004a,b; Rabe et al. 2004a,b). Patients enrolled in this trial received either placebo or roflumilast 250 or $500 \mathrm{mcg}$ once daily for 24 weeks. The second study included 516 patients ( $\mathrm{FEV}_{1} / \mathrm{FVC} \leq 70 \%$, postbronchodilator $\mathrm{FEV}_{1} 35-75 \%$ of predicted, and $F E V_{1}$ reversibility $<12 \%$ and $<200 \mathrm{~mL}$ ) who received either roflumilast 250 or $500 \mathrm{mcg}$ or placebo once daily for 26 weeks (Leichtl et al. 2002). Outcomes measured included lung function, exacerbation rate, quality of life, and tolerability. In addition, there is phase I evidence for outcomes related to the pharmacokinetic properties of roflumilast.

These results from clinical development give an indication of the effectiveness of roflumilast against key outcomes and areas of unmet need in COPD management.

\section{Once-daily dosing}

Evidence from roflumilast pharmacokinetic studies conducted in healthy volunteers support once-daily oral administration (Anon. 2004). Roflumilast is metabolized in the liver and its primary active metabolite, roflumilast $\mathrm{N}$-oxide, is responsible for much of its pharmacodynamic activity (Huennemeyer et al. 2002a). Following administration of roflumilast $500 \mathrm{mcg}$ to 18 healthy volunteers, the half-life of the parent compound was approximately $14 \mathrm{~h}$ (range

Table 4 | Commonly used tools to measure quality of life in patients with chronic obstructive pulmonary disease (de Torres et al. 2002; Desikan et al. 2002; Jones 2002; Wyrwich et al. 2003)

\begin{tabular}{|c|c|c|c|c|}
\hline Tool & No. of items & MCSD & Strengths & Weaknesses \\
\hline $\begin{array}{l}\text { Medical Outcomes } \\
\text { Study Short Form } 36 \\
\text { (SF-36) }\end{array}$ & $\begin{array}{l}36 \text { items covering } 8 \text { domains of } \\
\text { health based on WHO definitions } \\
\text { of health }\end{array}$ & $3-5$ points & $\begin{array}{l}\text { Generic } \\
\text { Good measure of general health } \\
\text { Can be self-administered or interviewer administered } \\
\text { Can be administered over the phone } \\
\text { Quick to administer ( } 5 \mathrm{~min})\end{array}$ & Not disease specific \\
\hline $\begin{array}{l}\text { Chronic Respiratory } \\
\text { Questionnaire (CRQ) }\end{array}$ & 20 items covering 4 subscales & 0.5 units & $\begin{array}{l}\text { Disease specific for chronic airflow limitation } \\
\text { Broadly measures physical and emotional function } \\
\text { Good reproducibility, validity, and responsiveness } \\
\text { Most responsive measure of change in } \mathrm{HRQOL}^{\mathrm{a}}\end{array}$ & $\begin{array}{l}\text { Individualized questions } \\
\text { Not standardized } \\
\text { Relatively long to administer } \\
\text { (15-25 min) }\end{array}$ \\
\hline $\begin{array}{l}\text { St George's } \\
\text { Respiratory } \\
\text { Questionnaire (SGRQ) }\end{array}$ & 76 items covering 3 subscales & 4 units & $\begin{array}{l}\text { Standardized; no individualized questions } \\
\text { Can be self- or interviewer administered } \\
\text { Intermediate to administer ( } 10 \text { min) }\end{array}$ & $\begin{array}{l}\text { Scoring pattern opposite of } \\
\text { SF-36 and CRQ; lower } \\
\text { numbers indicate better } \\
\text { overall health }\end{array}$ \\
\hline
\end{tabular}


Table 5 | Improvements in lung function with roflumilast observed in phase III studies

\begin{tabular}{|c|c|c|c|c|c|c|}
\hline Reference & Treatment (mcg) & $\mathbf{n}$ & $\mathrm{FEV}_{1}(\mathrm{~mL})$ & $\mathrm{FEV}_{6}(\mathrm{~mL})$ & PEF (L/min) ${ }^{b}$ & FVC $(m L)^{b}$ \\
\hline \multirow{3}{*}{$\begin{array}{l}\text { O'Donnell et al. } \\
\text { 2004b; Rabe et al. } \\
\text { 2004a }\end{array}$} & Placebo & 280 & NR & NR & NR & NR \\
\hline & Roflumilast 250 & 576 & $74 \pm 18^{a}$ & $95 \pm 24$ & NR & NR \\
\hline & Roflumilast 500 & 555 & $97 \pm 18^{a}$ & $135 \pm 25$ & NR & NR \\
\hline \multirow[t]{3}{*}{ Leichtl et al. 2002} & Placebo & 172 & $57^{\mathrm{b}}$ & NR & $2^{\mathrm{b}}$ & $-64^{b}$ \\
\hline & Roflumilast 250 & 175 & $93^{b}$ & NR & $9^{b}$ & $-3^{b}$ \\
\hline & Roflumilast 500 & 169 & $109^{b}$ & NR & $10^{\mathrm{b}}$ & $19^{b}$ \\
\hline \multicolumn{7}{|c|}{$\begin{array}{l}\text { almprovement in least-squares means } \pm \text { SEM compared to placebo, } P \leq 0.0001 \text {. } \\
\text { bChange in least-squares means from baseline. }\end{array}$} \\
\hline
\end{tabular}

9-22.8 h) (Manegold et al. 2002a), thus supporting once-daily dosing. Additionally, it does not appear that the timing of drug administration affects the pharmacokinetics of roflumilast, since the pharmacokinetics of both the parent drug and its active metabolite were similar when administered in either the morning or the evening (Hauns et al. 2003). This is in direct contrast to the oral administration of glucocorticoids; morning administration of oral corticosteroids is recommended to mimic the diurnal pattern of endogenous steroids.

Dosing is simplified further, as there were no effects on the area under the curve (AUC) of roflumilast or its major active metabolite when $500 \mathrm{mcg}$ was administered under either fed or fasted conditions in healthy subjects (Hauns et al. 2002).

\section{Lung function}

Measurement of pulmonary function in the clinical studies included $\mathrm{FEV}_{1}$, forced expiratory volume in $6 \mathrm{~s}\left(\mathrm{FEV}_{6}\right)$, peak expiratory flow (PEF), and forced vital capacity (FVC) (Leichtl et al. 2002; O'Donnell

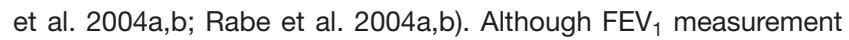
was reported in both phase III clinical trials (Table 5), other measures of pulmonary function were not consistently included in the initial study reports, making interpretation of findings difficult. Based on the preliminary data, however, changes in pulmonary function tests support roflumilast having a dose-dependent response curve.

Both doses of roflumilast improved $\mathrm{FEV}_{1}$ significantly $(P \leq 0.0001)$ compared with placebo and $\mathrm{FEV}_{6}$ improved significantly $(P=0.0051)$

Table 6 | Observed decrease in exacerbation rate with roflumilast

\begin{tabular}{|lcc|}
\hline & \multicolumn{2}{c|}{ Exacerbation rate (\% reduction vs placebo) } \\
\cline { 2 - 3 } & Roflumilast 250 mcg & Roflumilast 500 $\mathbf{~ m c g}$ \\
\hline $\begin{array}{l}\text { O'Donnell, et al. 2004a; } \\
\text { Press release 2004 } \\
(n=1411)\end{array}$ & 9 & 34 \\
$\begin{array}{l}\text { Leichtl et al. 2002 } \\
(n=516)\end{array}$ & 8 & 48 \\
\hline
\end{tabular}

versus baseline in those treated with roflumilast $500 \mathrm{mcg} /$ day for 24 weeks (O'Donnell et al. 2004a,b; Rabe et al. 2004a,b). Additionally, roflumilast improved or stabilized FVC, and PEF was rated significantly better according to patient diaries (Leichtl et al. 2002).

\section{Exacerbation rate}

There is evidence from phase III studies that roflumilast has a positive effect on exacerbation rate, a disease-oriented, secondary outcome. Compared with placebo, roflumilast decreased mean exacerbation rate by $8-9 \%$ at a dose of $250 \mathrm{mcg} /$ day, and by 34-48\% at $500 \mathrm{mcg} /$ day (Table 6) (Leichtl et al. 2002; O’Donnell et al. 2004a; Press release 2004). In a 26-week study, the mean rate of exacerbations per patient was 1.03 in recipients of the lower dose $(n=576)$, and 0.75 in those receiving the higher dose $(n=555)$, compared with 1.13 in the placebo group $(n=280 ; P=0.0029)$ (O'Donnell et al. 2004a; Press release 2004). Data from the second study is weaker as the number of exacerbations in both treatment arms was very low.

\section{Quality of life}

Evidence from the RECORD study indicates roflumilast has a positive impact on quality of life, a patient-oriented outcome (Table 7). There was a greater reduction in total St George's Respiratory Questionnaire (SGRQ) total score with roflumilast, indicating improved quality of life compared with placebo. Although the changes in total score were greater with both doses of roflumilast than with placebo and the difference was significant $(P \leq 0.025)$, no minimal clinically significant difference in reduction of SGRQ score was achieved by either dose.

\section{Tolerability and safety}

Information gathered during the RECORD trial indicates that roflumilast 250 and $500 \mathrm{mcg}$ were both well tolerated (Bateman et al. 2004). The most frequent drug-related adverse event reported (as assessed by the investigator) was diarrhea, occurring in $2 \%$ of the 250 mcg group $(n=576)$ and $6 \%$ of the 500 mcg group $(n=555$; statistical significance not reported). Other adverse events reported for patients in the 500 mcg group included nausea (6\%), abdominal pain $(3 \%)$, weight loss $(2 \%)$, headache $(2 \%)$, and dizziness $(2 \%)$. Overall, this profile is promising, with relatively low rates of adverse 
events compared with some of the other COPD treatment modalities (theophylline, glucocorticoids). The incidence and cause of weight loss will require additional research. Low body mass index and fat-free mass have been associated with increased morbidity and mortality from respiratory disease (Kilduff et al. 2003; Sutherland \& Cherniack 2004).

Evidence is also available from an additional 516 patients with COPD (Bredenbröker et al. 2002). Drug-related adverse events were transient and generally subsided with continued treatment. No severe or serious adverse events were considered to be related to roflumilast. Common adverse events in the placebo group $(n=172)$ and the roflumilast $500 \mathrm{mcg}$ group $(n=69)$, respectively, were headache (2 vs $4 \%$ ), abdominal pain (1 vs $3 \%$ ), nausea (2 vs $3 \%$ ), and diarrhea (0 vs 3\%) (Lipworth 2005).

Neither of the phase III studies revealed clinically significant changes in electrocardiogram (ECG) parameters or vital signs (Bredenbröker et al. 2002; Bateman et al. 2004). An additional study of roflumilast $500 \mathrm{mcg}$ daily in 12 healthy volunteers evaluated the impact of roflumilast on cardiac function and found no statistical or clinically significant differences between placebo- and roflumilasttreated patients with respect to changes in cardiac output, ECG, blood pressure, pulse rate, or heart rate corrected total electromechanical systole (Bethke et al. 2001).

\section{Drug interaction potential}

In studies evaluating possible drug interactions, roflumilast was not found to interact significantly with warfarin, inhaled salbutamol, inhaled budesonide, or erythromycin (Weimar et al. 2001; Huennemeyer et al. 2002a; Hauns et al. 2004a,b). In addition, the pharmacokinetics of roflumilast are not significantly influenced by smoking (Huennemeyer et al. 2002b). This lack of pharmacokinetic interactions offers an advantage of roflumilast treatment over theophylline, which is also available as an oral formulation. Use of theophylline is limited as a result of its toxicity and potential for drug interactions.

\section{Pending data}

The OPUS trial (1-year) is expected to be completed later in 2005 with data available in 2006. OPUS includes patients similar to those participating in the trials already reported in COPD; patients aged $\geq 40$ years with clinically stable COPD (FEV $1 / F V C$ ratio postbronchodilator $\leq 70 \%, \mathrm{FEV}_{1} \leq 50 \%$ of predicted, no long-term oxygen therapy) were eligible for enrollment. The study is designed to determine whether administration of roflumilast results in changes in the exacerbation rate, affects quality of life, or has an economic impact on the management of patients with COPD (OPUS 2005).

\section{Resource utilization}

The costs associated with the management of COPD continue to increase; direct medical and indirect costs (associated with premature morbidity and mortality) are considerable. At least onethird of patients with COPD report an inability to work or working time loss associated with their disease (Rennard et al. 2002). According to 2002 Medicare data, healthcare expenses for patients with COPD were almost 2.5 times those of other patients (NHLBI 2005). Disease that is not well controlled places patients at risk of
Table 7 | Quality of life scores from RECORD study (O'Donnell et al. 2004a)

\begin{tabular}{|lcc|} 
& $\mathbf{n}$ & $\begin{array}{c}\text { Change in SGRQ } \\
\text { scores from baseline }\end{array}$ \\
\hline Placebo & 280 & -1.79 \\
Roflumilast $250 \mathrm{mcg}$ & 576 & -3.25 \\
Roflumilast $500 \mathrm{mcg}$ & 555 & -3.51 \\
\hline SGRQ, St George's Respiratory Questionnaire.
\end{tabular}

developing exacerbations, many of which translate to increased healthcare spending for hospitalization (Vermiere 2002). In one study, approximately $90 \%$ of the costs associated with an exacerbation related to hospitalization (Oostenbrink \& Rutten-van Molken 2004). Beyond the actual economic costs of these hospitalizations, the hospital stays themselves are associated with increased mortality, especially in those $>65$ years and those who require admission to an intensive care unit (Afessa et al. 2002; Almagro et al. 2002).

Since a considerable portion of the expenditures related to COPD is associated with the management of disease exacerbations, treatments that can reduce the number experienced would be expected to decrease costs. Preliminary evidence indicates that roflumilast $500 \mathrm{mcg}$ results in a $34 \%$ decrease in exacerbations compared with placebo. This decrease may directly reduce hospitalization costs, as well as indirectly decreasing the economic burden caused by loss of work for both patients and their caregivers, and the costs associated with premature morbidity. The OPUS trial may provide additional evidence on the economic impact of roflumilast use.

\section{Patient group/population}

Roflumilast has the potential to be used in a large segment of the COPD population. COPD is one of the leading causes of morbidity and mortality, occurring in approximately $10 \%$ of the population in the developed world (Halbert et al. 2003). Most patients with COPD are over 45 years of age and have other comorbid disease states, which complicate therapy because of the need for additional medications and the potential for physical/cognitive limitations. Age can also affect the pharmacokinetics of medications. However, although the area under the plasma concentration curve for roflumilast was higher in healthy volunteers aged 45-64 years than in volunteers aged 22-30 years, the difference was not clinically important and no dosage adjustment is recommended in older patients (Manegold et al. 2002b).

The once-daily oral administration of roflumilast will offer patients an alternative to inhaled therapies and medication regimens that require more frequent dosing. The effectiveness of inhaled therapies is dependent upon correct techniques and the ability to self-actuate devices without significant difficulty. As patients age, the use of inhalers may become more difficult, not only because of physical limitations associated with aging, such as arthritis, but also because of cognitive decline that some may experience. Use of an oral agent, like roflumilast, may obviate these issues in patients with COPD. Likewise, this group of patients usually has declining renal function 
associated with the aging process, which may also be exacerbated by other comorbid conditions. Since dosing of roflumilast does not appear to be affected by declining renal function (Bethke et al. 2002), it can be administered without the need for dosage adjustment or the need to monitor renal function.

There is an additional concern with currently available COPD medications in patients with progressive disease who develop cor pulmonale or pulmonary hypertension. Bronchodilators can have a negative impact on cardiac work and thus aggravate cardiac disease. Currently, the impact of roflumilast in patients with cor pulmonale and pulmonary hypertension is not known; no studies with roflumilast have included such patients. However, based on the limited evidence of roflumilast in healthy volunteers, the drug does not appear to have any cardiac effects. It may, therefore, be useful in patients with cor pulmonale or pulmonary hypertension; however, this will have to be evaluated in studies in these specific patient populations.

\section{Clinical potential}

The preliminary data reported to date indicate that roflumilast, which offers a unique antiinflammatory mechanism of action in an oral formulation, is effective in decreasing symptoms associated with moderate-to-severe COPD, and may possess clinical potential in the management of the disease. This is supported by level 2 evidence from early reporting of two randomized controlled trials in abstract form. At this early stage of development of the drug with the available data, the strength of the evidence cannot be evaluated.

Although bronchodilators are currently the cornerstone of therapy for patients with COPD, they either have to be administered by inhalation or, in the case of theophylline, are associated with significant toxicities and drug-drug and drug-disease interactions. Glucocorticoids may be administered orally, but because of the potential for adverse effects, should be reserved for acute exacerbations. Roflumilast has not been associated with significant drug interactions and the adverse events associated with its use have generally been transient and mild to moderate in intensity. Roflumilast may therefore offer the advantages of a convenient oral treatment option without the tolerability issues associated with glucocorticoids and theophylline.

The early evidence therefore supports the use of roflumilast in COPD. Its place in the stepwise approach to management of the disease should become clearer as the randomized trial evidence is published in full, but it has the potential to be used in early stages of the disease, and not reserved for acute exacerbations. Of particular interest will be additional evidence to determine if its unique mechanism of action moderates the progression of lung function deterioration and the clinical advantages this may offer over the current treatments.

\section{References}

Aaron SD, Vandeinheen KL, Clinch JJ, et al. Measurement of short-term changes in dyspnea and disease-specific quality of life following an acute COPD exacerbation. Chest. 2002;121:688-696.

Afessa B, Morales I, Scanlon P, Peters S. Prognostic factors, clinical course, and hospital outcome of patients with chronic obstructive pulmonary disease admitted to an intensive care unit for acute respiratory failure. Crit Care Med. 2002;30:1610-1615.
Alsaeedi A, Sin DD, McAlister FA. The effects of inhaled corticosteroids in chronic obstructive pulmonary disease: a systematic review of randomized placebocontrolled trials. Am J Med. 2002;11:59-65.

Almagro P, Calbo E, Ochoa de Echaguen A, et al. Mortality after hospitalization for COPD. Chest. 2002;121:1441-1448.

Anon. Roflumilast. Drugs R\&D. 2004;5:176-181.

ATS (American Thoracic Society) and ERS (European Respiratory Society). Standards for the diagnosis and management of patients with chronic obstructive pulmonary disease. Available at: http://www.thoracic.org/copd/pdf/copddoc.pdf (accessed January 18, 2005).

Barnes PJ. Theophylline. New perspectives for an old drug. Am J Respir Crit Care Med. 2003;167:813-818.

Bateman E, Holmes M, Muir J, Andrae K, Witte S, Bredenbroeker D. Safety profile of roflumilast, a novel selective phosphodiesterase 4 inhibitor, in patients with moderate to severe COPD. Presented at the American Thoracic Society Annual Meeting; May 25: Orlando, FL. Poster number F17; 2004.

Bethke T, Hartmann M, Baumgartner A, Eichberger C, Hauns B, Wurst W. The new PDE4 inhibitor roflumilast does not influence cardio-vascular function. Presented at the American Thoracic Society Annual Meeting; San Francisco, CA; 2001.

Bethke T, Hartmann M, Zech K, David M, Weimar C, Wurst W. No dose adjustment of roflumilast in patients with severe renal impairment. Presented at the American Thoracic Society Annual Meeting; Atlanta, GA; 2002.

Bonay M, Bancal C, Crestani B. The risk/benefit of inhaled corticosteroids in chronic obstructive pulmonary disease. Expert Opin Drug Saf. 2005;4:251-271.

Bredenbröker D, Syed J, Leichtl S, Rathgeb F, Wurst W. Safety of once-daily roflumilast, a new, orally active, selective phosphodiesterase 4 inhibitor, in patients with COPD. Presented at the American Thoracic Society Annual Meeting; Atlanta, GA; 2002.

Briggs DD. Chronic obstructive pulmonary disease overview: Prevalence, pathogenesis, and treatment. J Manag Care Pharm. 2004;10 (Suppl S-a):S3-S10.

de Torres JP, Pinto-Plata V, Ingenito E, et al. Power of outcome measurements to detect clinically significant changes in pulmonary rehabilitation of patients with COPD. Chest. 2002;121:1092-1098.

Desikan R, Mason H, Rupp M, Skehan M. Health-related quality of life and healthcare resource utilization by COPD patients: A comparison of three instruments. Qual Life Res. 2002;11:739-751.

Domingo-Salvany A, Lamarca R, Ferer M, et al. Health-related quality of life and mortality in male patients with chronic obstructive pulmonary disease. Am J Resp Crit Care Med. 2002;166:680-685.

Fan VS, Curtis JR, Tu S-P, McDonell MB, Fihn SD. Using quality of life to predict hospitalization and mortality in patients with obstructive lung diseases. Chest. 2002;122:429-436.

Gamble E, Grootendorst DC, Brightling CE, et al. Antiinflammatory effects of the phosphodiesterase-4 inhibitor cilomilast (Ariflo) in chronic obstructive pulmonary disease. Am J Respir Crit Care Med. 2003;168:976-982.

GOLD (Global Initiative for Chronic Obstructive Lung Disease), WHO (World Health Organization), NHLBI (National Heart, Lung and Blood Institute). Global strategy for the diagnosis, management, and prevention of chronic obstructive pulmonary disease. Bethesda, MD. Global Initiative for Chronic Obstructive Lung Disease, World Health Organization, National Heart, Lung and Blood Institute; 2004.

Halbert R, Isonaka S, George D, Igbal A. Interpreting COPD prevalence estimates. What is the true burden of disease? Chest. 2003;123:1684-1692.

Hauns B, Bethke T, Huennemeyer A, Hartmann M, Zech K, Wurst W. Influence of food intake on the pharmacokinetics of roflumilast and its active metabolite roflumilast- $n$-oxide. Presented at the American Thoracic Society Annual Meeting; Atlanta, GA; 2002.

Hauns B, Huennemeyer A, Seiberling M, et al. Pharmacokinetics of roflumilast and roflumilast $\mathrm{N}$-oxide in healthy subjects after a single, oral dose of $500 \mathrm{mcg}$ roflumilast in the morning versus evening. Eur Respir J. 2003;22(Suppl. 45):102s.

Hauns B, Huennemeyer A, Duursema L, et al. Lack of pharmacokinetic interaction between roflumilast and concomitant warfarin. Presented at the American Thoracic Society Annual Meeting; May 25: Orlando, FL. Poster number F88; 2004a. 
Hauns B, Huennemeyer A, Koch M, Manegold A, Zech K, Bethke T. Lack of pharmacokinetic drug interaction between roflumilast and erythromycin. Presented at the American Thoracic Society Annual Meeting; May 25: Orlando, FL. Poster number F87; 2004b.

Highland KB, Strange C, Heffner JE. Long-term effects of inhaled corticosteroids on Fev1 in patients with chronic obstructive pulmonary disease. Ann Intern Med. 2003;138:969-973.

Huennemeyer A, Bethke T, David M, Westphal K, Siegmund W, Wurst W. No interaction of roflumilast and its active metabolite, roflumilast- $n$-oxide, with inhaled budesonide. Presented at the American Thoracic Society Annual Meeting; Atlanta, GA; 2002a.

Huennemeyer A, Hauns B, Drollmann A, et al. Pharmacokinetics of roflumilast and its active metabolite, roflumilast- $n$-oxide, is not influenced by smoking. Presented at the American Thoracic Society Annual Meeting; Atlanta, GA; 2002b.

Jones $P$. Interpreting thresholds for a clinically significant change in health status in asthma and COPD. Eur Respir J. 2002;19:398-404.

Kilduff LP, Neder JA, Pitsiladis YP, et al. Clinical relevance of inter-method differences in fat-free mass estimation in chronic obstructive pulmonary disease. Respiration. 2003;70:585-593.

Leichtl S, Syed J, Bredenbroeker D, Rathgeb F, Wurst W. Efficacy of once-daily roflumilast, a new, orally active, selective phosphodiesterase 4 inhibitor, in chronic obstructive pulmonary disease. Presented at the American Thoracic Society Annual Meeting; Atlanta, GA; 2002.

Lipworth BJ. Phosphodiesterase-4 inhibitors for asthma and chronic obstructive pulmonary disease. Lancet. 2005;365:167-175.

Make BJ. Chronic obstructive pulmonary disease: Developing comprehensive management. Respir Care. 2003;48:1225-1234.

Manegold A, Hauns B, David M, Zech K, Bethke T, Wurst W. Pharmacokinetic characteristics of roflumilast administered in gradually increasing doses of 500 $\mathrm{mcg}$ to $1000 \mathrm{mcg}$ are dose-linear in healthy subjects. Eur Respir $\mathrm{J}$. 2002a;20(Suppl. 38):108s.

Manegold A, Huennemeyer A, Zech K, et al. Pharmacokinetics of roflumilast and its active metabolite roflumilast-N-oxide in middle aged and young subjects. Eur Respir J. 2002b;20(Suppl. 38):109s.

Miravitlles M, Alvarez-Sala J, Lamarca R, et al. Treatment and quality of life in patients with chronic obstructive pulmonary disease. Qual Life Res. 2002;11:329-338.

Murray C, Lopez A. Alternative projections of mortality and disability by cause 1990-2020: Global Burden of Disease Study. Lancet. 1997;349:1498-1504.

NHLBI (National Heart Lung and Blood Institute). Chronic obstructive pulmonary disease. Available at:

http://www.nhlbi.nih.gov/health/public/lung/other/copd_fact.pdf (accessed

January 18, 2005).

NICE (National Institute for Health and Clinical Excellence). Chronic obstructive pulmonary disease. Management of chronic obstructive pulmonary disease in primary and secondary care. Available at: http://www.nice.org.uk/pdf/CG012_niceguideline.pdf (accessed January 18, 2004).

O'Donnell D, Muir J, Jenkins C, et al. Roflumilast, a novel, selective phosphodiesterase 4 inhibitor, improves quality of life and lowers exacerbation rate in patients with moderate to severe COPD. Presented at the American Thoracic Society Annual Meeting; Orlando, FL. Poster number J58; 2004a.
O'Donnell D, Rabe K, Jenkins C, Muir J, Witte S, Bredenbroeker D. FEV 6 : a useful outcome measure of lung function in COPD as assessed in a large clinical study with roflumilast. Presented at the European Respiratory Society Annual Congress; September 6: Glasgow, Scotland. Poster number 2151; 2004b.

Oostenbrink J, Rutten-van Molken M. Resource use and risk factors in high-cost exacerbations of COPD. Respir Med. 2004;98:883-891.

OPUS study. Effect of roflumilast on exacerbation rate in patients with chronic obstructive pulmonary disease. Available at: http://www.clinicaltrials.gov. (accessed January 18, 2005).

Pauwels R, Rabe KF. Burden and clinical features of chronic obstructive pulmonary disease (COPD). Lancet. 2004;364:613-620.

Press release. Additional positive roflumilast data of RECORD study at German Congress for Pneumonology, 2004. Available at: http://www.altanapharma.com/home/site.nsf/files/e_2_news.04-03-12.html.

Rabe K, Chapman K, Joubert J, Vetter N, Witte S, Bredenbroeker D. Roflumilast, a novel, selective phosphodiesterase 4 inhibitor, improves lung function in patients with moderate to severe COPD. Presented at the American Thoracic Society Annual Meeting; Orlando, FL. Poster number 509; 2004a.

Rabe K, O'Donnell D, Muir J, et al. Roflumilast, an oral, once-daily PDE4 inhibitor, improves lung function and reduces exacerbation rates in patients with COPD. Presented at the European Respiratory Society Annual Congress; September 5: Glasgow, Scotland. Poster number 267; 2004b.

Rennard S, Decramer M, Calverley P, et al. Impact of COPD in North America and Europe in 2000: subjects' perspective of Confronting COPD International Survey. Eur Respir J. 2002;20:799-805.

Soto FJ, Hanania NA. Selective phosphodiesterase-4 inhibitors in chronic obstructive lung disease. Curr Opin Pulm Med. 2005;11:129-134.

Spina D. Phosphodiesterase-4 inhibitors in the treatment of inflammatory lung disease. Drugs. 2003;63:2575-2584.

Sturton G, Fitzgerald M. Phosphodiesterase 4 inhibitors for the treatment of COPD. Chest. 2002;121:192S-196S.

Sutherland ER, Cherniack RM. Management of chronic obstructive pulmonary disease. N Engl J Med. 2004;350:2689-2697.

Vermiere P. The burden of chronic obstructive pulmonary disease. Respir Med. 2002;96(Suppl. C):S3-S10.

Weimar C, Westphal K, Bethke T, et al. No interaction of roflumilast, a new, orally active, selective PDE4 inhibitor, with inhaled salbutamol. Presented at the European Respiratory Society Annual Congress; September 23: Berlin, Germany. Poster number 1059; 2001

WHO (World Health Organization). World Health Report 2002. Available at: http://www.who.int/whr/2002 (accessed January 25, 2005).

Wyrwich KW, Finn SD, Tierney WM, Kroenke K, Babu A, Wolinsky FD. Clinically important changes in health-related quality of life for patients with chronic obstructive pulmonary disease. An expert consensus panel report. $J$ Gen Intern Med. 2003;18:196-202.

Correspondence: Doris Peter, Core Medical Publishing, 445 Hamilton Avenue, Suite 1102, White Plains, New York, NY 10601, USA or at editor@coreevidence.com 